\title{
Use of antimesothelial cell antibody and computer assisted quantitative analysis for distinguishing between reactive and neoplastic serosal tissues
}

\author{
A DONNA, P G BETTA, F ROBUTTI \\ From the Department of Pathology, City Hospital, Alessandria, Italy
}

SUMMARY Nine malignant mesotheliomas and 12 specimens of benign reactive mesothelial hyperplasia were examined using a specific antimesothelial cell antibody. Immunostaining intensity was subsequently estimated by means of image analysis. The mean and standard deviation of integrated optical density in the malignant mesotheliomas differed significantly from those in the mesothelial hyperplasias. In all mesotheliomas but one the integrated optical density was greater than in reactive mesothelial hyperplasia. No significant difference in optical density was observed between the two groups; the standard deviation was significantly higher in the reactive lesions.

This technique may be adopted to complement the traditional morphological assessment of primary lesions of the serosal cavities.

We recently reported the diagnostic value of a novel polyclonal antibody raised against a protein isolated from the cytoplasm of mesothelioma cells, ${ }^{1}$ and shown to be peculiar to this tumour. ${ }^{2}$ As this antibody also reacted with hyperplastic mesothelial cells, however, a clear cut distinction between reactive and malignant serosal tissues was not possible (fig 1), especially when intensity of immunostaining was graded subjectively.

In the study reported here we investigated the use of computer assisted densitometry, applied to immunostained histological preparations, to determine whether an objective quantitation of the intensity of immunostaining could assist the differentiation between reactive and malignant mesothelial cells.

\section{Material and methods}

Nine cases of malignant mesothelioma and 12 specimens of benign reactive mesothelial hyperplasia were included in the study. The mesothelioma cases had been previously reviewed and classified by the Commission of the European Communities Mesothelioma Panel. All specimens had been obtained at surgery or at necropsy. Five micron sections from tissues embedded in paraffin and fixed in $10 \%$ formalin

Accepted for publication 25 June 1987 were cut with a rotative microtome, deparaffinised and rehydrated. These sections were then simultas neously stained with immunoperoxidase using a teck nique described previously, ${ }^{1}$ using samples from $\vec{a}^{+}$ single stock of the primary polyclonal antimesothelial cell antibody.

Intensity of cytoplasmic staining of $\mathbf{3 0 0}$ mesothelial cells was estimated in each case by measuring the optical density and the integrated optical density with an image analysis system (Zeiss Kontron IBAS 2000). Optical density is defined as the negative logarithm (base 10) of the percentage ratio of transmitted light to incident light

$$
\text { (optical density }=-\log _{10} \frac{\mathrm{L}_{\mathrm{T}}}{\mathrm{L}_{\mathrm{I}}} \times 100 \text { ). }
$$

Its range in the IBAS 2000 is between 0 and 2.55.

Integrated optical density is defined as the product of optical density and the area (in pixel units) (integrated optical density $=$ optical density $\times$ area) and this parameter is directly related to either the relative or the absolute mass of material in a microscopic specimen using incident light.

Statistical analysis of the mean optical density and integrated optical density values and the standard deviations (SD) of the $\mathbf{3 0 0}$ measured cells of each case was carried out, and Student's $t$ test was used to establish the significance of the differences in intensity of immunostaining between the two groups. A p value of $<0.05$ was regarded as significant.

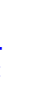




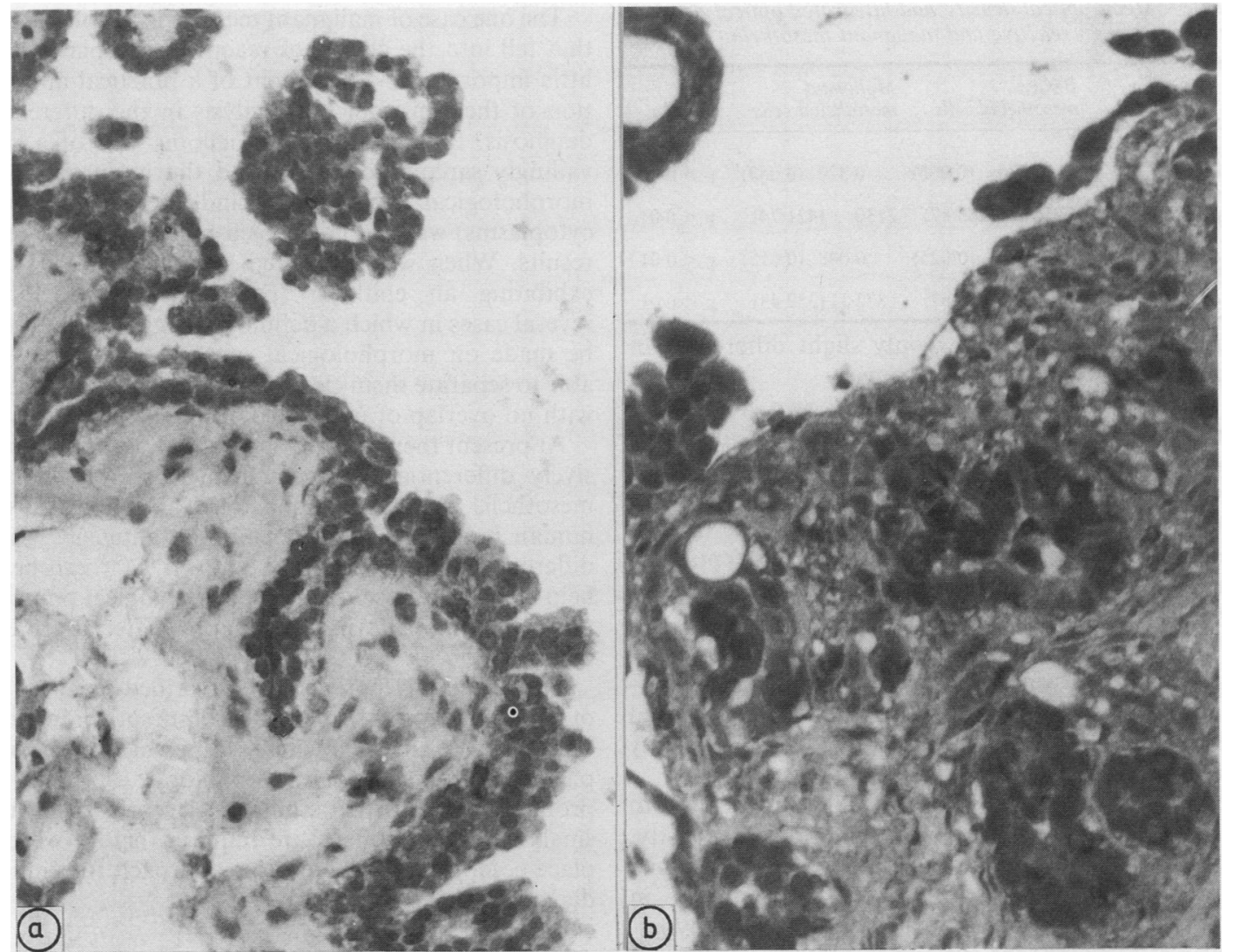

Fig 1 Reactive hyperplastic mesothelium (a) and malignant mesothelium (b) show positive immunostaining for the antimesothelial cell antibody (PAP-immunoperoxidase).

\section{Results}

The table shows the assessment of staining intensity of the mesothelial cells. A scattergram was made of all the results (fig 2).

The optical density ranged from 0.220 to 0.370 for the mesotheliomas and from 0.260 to 0.430 for the mesothelial hyperplasia. No significant difference $(p>0 \cdot 10)$ was observed between the two groups. All the malignant mesotheliomas but one, however, fell in one cluster with high integrated optical density values (1742-2756); all the reactive serosal lesions had low integrated optical density values (849-1669), the difference between the two groups being highly significant $(p<0.01)$. Optical density and integrated optical density standard deviations showed significant differences $(p<0.01)$. One mesothelioma fell near (integrated optical density of 1455) the upper edge of the reactive cluster (integrated optical density of 1669), and quite close to the lower limit of the mesothelioma cluster (integrated optical density of 1742).

\section{Discussion}

A considerable overlap exists between the histological and cytological characteristics of non-neoplastic reactive serosal tissues and well differentiated mesothelioma. Morphometry ${ }^{34}$ and immunocytochemistry ${ }^{5-13}$ have been claimed to have value in distinguishing mesothelioma from reactive mesothelium. Kwee et al advocated quantitative assessment of mesothelial cells in pleural effusions based on the measurement of nuclear and cytoplasmic areas. In fact, both nuclear and cytoplasmic mean areas were found to be significantly greater in mesothelioma than in reactive mesothelial cells, but nine of 60 cases could not be properly diagnosed using quantitative variables alone, giving a success rate of only $85 \%$ in defining the nature of proliferating mesothelial cells. This lack of absolute accuracy in differential diagnosis is due, in our opinion, to the fact that both benign reactive and malignant mesothelial cells tend to assume a globular shape because they float in effusion 
Table Mean optical density and integrated optical density values of benign reactive and malignant mesothelial lesions

\begin{tabular}{lccccc}
\hline & $\begin{array}{l}\text { Benign } \\
\text { mesothelial cells }\end{array}$ & $\begin{array}{l}\text { Malignant } \\
\text { mesothelial cells }\end{array}$ & $p$ Value \\
\hline $\begin{array}{l}\text { Mean optical } \\
\text { density }\end{array}$ & 0.326 & $(0.065)$ & $0.320(0.050)$ & $\mathrm{p}>0.10$ \\
$\begin{array}{c}\text { Mean integrated } \\
\text { optical density }\end{array}$ & $1203.17 \quad(238.87)$ & $2130 \quad(421.74)$ & $\mathrm{p}<0.01$ \\
$\begin{array}{c}\text { SD optical } \\
\text { density }\end{array}$ & 0.078 & $(0.025)$ & $0.048(0.015)$ & $\mathrm{p}<0.01$ \\
$\begin{array}{l}\text { SD integrated } \\
\text { optical density }\end{array}$ & 454.92 & $(93.57)$ & $872.11(359.43)$ & $\mathrm{p}<0.01$ \\
\hline
\end{tabular}

fluids and therefore show only slight differences in nuclear and cytoplasmic diameters.

Nuclear size has also been shown to be an important discriminator between reactive and neoplastic serosal tissues in histological preparations. Kwee et $\mathrm{al}^{4}$ measured morphometrically the nuclear size of mesothelial cells in both types of the tissues, and in the reactive lesions alone, with the exception of one case, were the nuclear areas found to be below $30 \mu \mathrm{m}^{2}$.

Our findings showed that there was a significant difference between reactive and malignant proliferations when the integrated optical density was used as the discriminating variable; the optical density could not distinguish the two entities.

As integrated optical density values are related to the cytoplasmic areas in opposition to optical density, which is an absolute variable, our results confirmed the role of measuring cytoplasmic area in differentiating mesothelioma from reactive hyperplasia. ${ }^{3}$ A significant difference was also observed between the two mean values of optical density standard deviations in the two groups of lesions. This densitometric finding could possibly be due to an uneven distribution of the antigen in the cytoplasm of reactive mesothelial cells. This distribution, however, would be uniform in malignant cells.

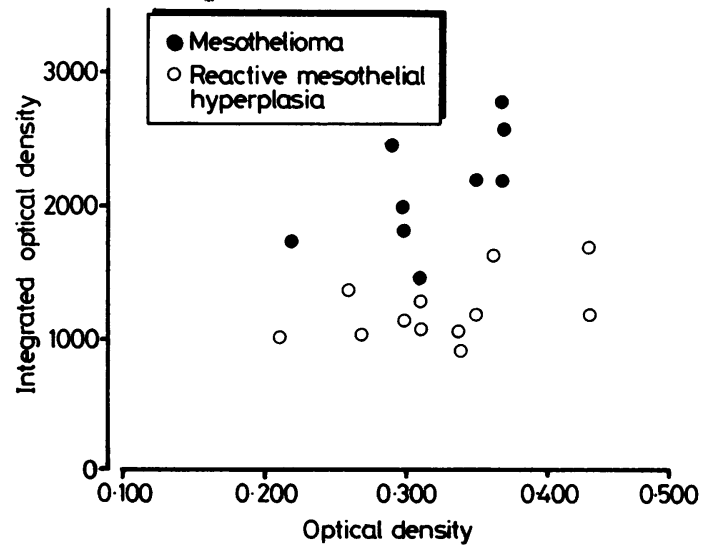

Fig 2 Scattergram of all cases comparing optical density with integrated optical density.
The one case of malignant mesothelial proliferation that fell into the cluster of reactive hyperplasia is of little importance-in the light of a practical application of the densitometric analysis in the differential diagnosis. In fact, this mesothelioma was of a prevailingly sarcomatous type and the unquestionable morphological appearance (spindle cells with scanty cytoplasms) was not challenged by the densitometric results. When we considered separately the lesions exhibiting an epithelial pattern, which included several cases in which a definitive diagnosis could not be made on morphological criteria alone, we were able to separate them clearly into two discrete clusters with no overlap of integrated optical density values.

At present there are no techniques that can conclusively differentiate between benign and malignant mesothelia. Although monoclonal antibodies to the human milk fat globule membrane antigen ${ }^{810}$ and different determinants of $\mathrm{Ca}$ antigen ${ }^{1-13}$ can be of help in making this distinction in cytological preparations, the findings with histological material are less convincing. ${ }^{9}$

The technique that we have described seems to be of value in histological diagnosis of mesothelioma but only as one of many ancillary tests which may complement the traditional morphology, especially in problem cases. Further studies with serous fluids and small biopsy specimens are required before we can place complete reliance on this approach for clinical diagnosis.

\section{References}

1 Donna A, Betta PG, Bellingeri D, Marchesini A. New marker for mesothelioma: an immunoperoxidase study. J Clin Pathol 1986;39:961-8.

2 Donna A, Betta PG, Marchesini A. Isolation and characterization of a possible new protein marker for differential diagnosis between metastatic carcinoma and mesothelioma cells in serous effusions: preliminary findings. Cancer Detect Prev 1985;8: 255-60.

3 Kwee WS, Veldhuizen RW, Alons CL, Morawetz F, Boon ME. Quantitative and qualitative differences between benign and malignant mesothelial cells in pleural fluid. Acta Cytol 1982;26:401-6.

4 Kwee WS, Veldhuizen RW, Golding RP, et al. Histologic distinction between malignant mesothelioma, benign pleural lesion and carcinoma metastasis. Evaluation of the application of morphometry combined with histochemistry and immunostaining. Virchows Arch (Pathol Anat) 1982;397:287-99.

5 To A, Dearnaley DP, Ormerod MJ, Canti G, Coleman DV. Indirect immunoalkaline phosphatase staining of cytologic smears of serous effusions for tumour marker studies. Acta Cytol 1983;27:109-13.

6 Ashall F, Bramwell ME, Harris H. A new marker for human cancer cells: 1. The $\mathrm{Ca}$ antigen and the $\mathrm{Ca} /$ antibody. Lancet 1982;ii: $1-6$.

7 Herbert A, Gallagher PJ. Interpretation of pleural biopsy specimens and aspirates with the immunoperoxidase technique. Thorax 1982;37:822-7.

8 Marshall RJ, Herbert A, Braye SG, Jones DB. Use of antibodies 
to carcinoembryonic antigen and human milk fat globule to distinguish carcinoma, mesothelioma, and reactive mesothelium. J Clin Pathol 1984;37:1215-21.

9 Ghosh AK, Gatter KC, Dunnil MS, Mason DY. Immunohistological staining of reactive mesothelium, mesothelioma, and lung carcinoma with a panel of monoclonal antibodies. $J$ Clin Pathol 1987;40:19-25.

10 Epenetos AA, Canti G, Taylor-Papadimitriou J, Curling M, Bodmer WF. Use of two epithelium-specific monoclonal antibodies for diagnosis of malignancy in serous effusions. Lancet 1982;ii:1004-6.

11 Ghosh AK, Spriggs AI, Taylor-Papadimitriou J, Mason DY. Immunocytochemical staining of cells in pleural and peritoneal effusions with a panel of monoclonal antibodies. J Clin Pathol
1983;36:1154-64.

12 Woods JC, Spriggs AI, Harris H, McGee JO'D. A new marker for human cancer cells. 3. Immunocytochemical detection of malignant cells in serous fluids with the $\mathrm{Ca} 1$ antibody. Lancet 1982;ii:512-5.

13 Bramwell ME, Ghosh AK, Smith WD, Wiseman G, Spriggs AI, Harris $\mathrm{H}$. Ca 2 and $\mathrm{Ca} 3$ : new monoclonal antibodies evaluated as tumour markers in serous effusions. Cancer 1985;56:105-10.

Requests for reprints to: Professor A Donna, Department of Pathology, City Hospital, USSL 70, Via Venezia 18, 15100 Alessandria, Italy. 